\title{
Effect on nasal resistance of an external nasal splint and isotonic exercise
}

\author{
A D Wilde, S R Ell
}

\begin{abstract}
Objectives-The now commonplace wearing of external nasal splints by sportsmen and athletes has never been scientifically evaluated. The present study looks into the effect of isotonic exercise on nasal resistance, and examines whether this effect is altered by the wearing of an external nasal splint.

Methods-Twenty subjects not suffering from rhinitis were tested. Nasal resistance measurements were recorded using an anterior rhinomanometer before and after isotonic exercise with and without an external nasal splint. Pulse and blood pressure were measured before and after exercise.

Results-Significant changes were observed in pulse $(p<0.001)$ and both systolic $(p<0.002)$ and diastolic $(p<0.001)$ blood pressure in response to exercise. Significant differences were seen in nasal resistance when the splint was applied $(p<0.001)$ and after exercise $(p<0.003)$. No significant difference was observed after exercise when the splint was worn $(p=0.167)$. Conclusions-External nasal splints decrease nasal resistance at rest but are of little value during isotonic exercise. (Br F Sports Med 1999;33:127-128)
\end{abstract}

Keywords: isotonic exercise; nasal resistance; nasal valve; nasal splint

The common practice in sportsmen and women of wearing a splinting device to widen the nasal valve has not been scientifically evaluated. The nasal valve has long been known to be the narrowest part of the nose, and therefore any alteration in its cross sectional area will have a profound effect on inspiratory nasal resistance. ${ }^{12}$ The nasal effects of isotonic exercise have been extensively studied, and it is known to cause marked nasal decongestion such that even only moderate exercise causes a halving of nasal resistance to airflow. ${ }^{3}$

This study attempts to evaluate the decrease in nasal resistance caused by an external nasal splint and to see if this decrease is sustained during isotonic exercise.
Methods

Subjects included in the study had not suffered from two or more of the following symptoms for the preceding two years: perennial nasal obstruction, rhinorrhoea, and sneezing. A serum non-specific IgE level of less than 40 $\mathrm{IU} / \mathrm{ml}$ was also an inclusion criterion unless specific IgE to cat dander, dog dander, house dust mite, and grass pollen were negative, in which case a total serum IgE level of $100 \mathrm{IU} / \mathrm{ml}$ was accepted. If serum IgE was higher than 100 $\mathrm{IU} / \mathrm{ml}$, a battery of skin prick tests was performed, all of which had to be negative (except for the histamine control) to permit inclusion. Nasal cytology was also required to show a differential eosinophil count of less than $20 \%$, expressed as a proportion of total inflammatory cells present in a well populated microscopic field. Subjects with non-allergic rhinitis with eosinophilia syndrome were therefore excluded.

Baseline measurements of pulse and blood pressure were recorded using a Criticare Inc model 508 physiological monitor (R L Dolby \& Co, Dunblane, Scotland, UK). Resting nasal resistance to airflow was recorded by active anterior rhinomanometry using a Mercury NR6 Rhinomanometer (GM Instruments Ltd, Kilwinning, Scotland, UK) and the method described by Jones et al. ${ }^{4}$ The subject was then asked to run up and down a flight of stairs for two minutes, at the end of which time the pulse, blood pressure, and nasal resistance were again recorded. The subject was given a 20 minute rest while the face mask was adjusted to assess the opposite nostril, and the test was then repeated. An external nasal splint was

Table 1 Median changes in pulse, blood pressure, and total inspiratory nasal resistance due to isotonic exercise and nasal splints

\begin{tabular}{ll}
\hline Variable measured & Change \\
\hline $\begin{array}{l}\text { Change due to exercise } \\
\text { Pulse (beats/min) }\end{array}$ & $62.5(71-55.75)$ \\
$\begin{array}{l}\text { Systolic blood pressure }(\mathrm{mm} \mathrm{Hg}) \\
\text { Diastolic blood pressure }(\mathrm{mm} \mathrm{Hg}) \\
\text { Total inspiratory nasal resistance } \\
\quad\left(\mathrm{kPa} . \mathrm{s} / \mathrm{dl}^{2}\right)\end{array}$ & $21(24-14)$ \\
$\begin{array}{l}\text { Change due to splint } \\
\text { Total inspiratory nasal resistance } \\
\left(\mathrm{kPa} / \mathrm{s} / \mathrm{dl}^{2}\right)\end{array}$ & $0.162(0.202-0.106)$ \\
$\begin{array}{l}\text { Change due to exercise and splint } \\
\text { Total inspiratory nasal resistance } \\
\left(\mathrm{kPa} / \mathrm{s} / \mathrm{dl}^{2}\right)\end{array}$ & $0.199(0.279-0.144)$ \\
\hline
\end{tabular}




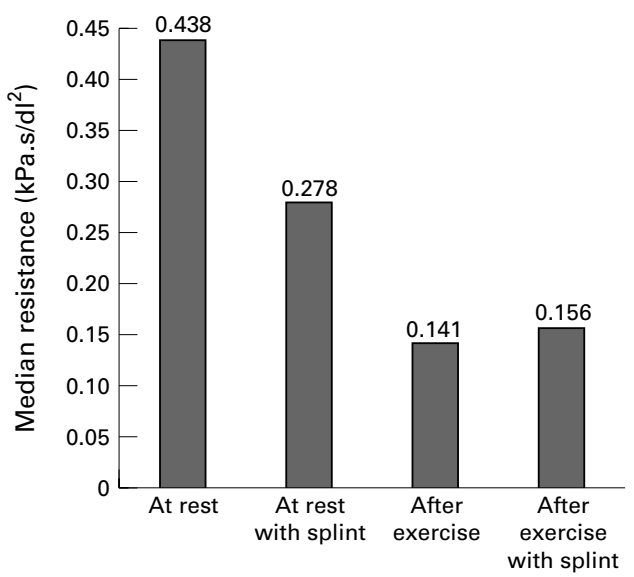

Figure 1 Histogram showing the effect on total inspiratory nasal resistance ( $\left.\mathrm{kPa} . \mathrm{s} / \mathrm{dl}^{2}\right)$ of wearing a nasal splint before and after isotonic exercise.

then applied and measurements were again made before and after exercise.

Calculations of total nasal resistance were made from the inspiratory measurements for both nostrils. All data obtained were entered on to a spreadsheet (Microsoft Excel) before statistical analysis using a proprietry statistical package (SPSS for windows). The data were tested for normality and found to be not normally distributed; therefore non-parametric methods (Wilcoxon signed rank test) were used.

\section{Results}

There was a significant rise in pulse $(p<0.001)$ and significant falls in both systolic and diastolic blood pressure $(p=0.015$ and $p<0.001$ respectively) in both groups but no differences between the groups, showing that a significant amount of isotonic exercise was performed in this test. ${ }^{5}$

All patients were able to complete the tests. Table 1 and fig 1 illustrate the effects of isotonic exercise on median values of total inspiratory nasal resistance to airflow. The response to isotonic exercise in normal subjects is a decrease in total inspiratory nasal resistance (median fall $=0.162 \mathrm{kPa} . \mathrm{s} / \mathrm{dl}^{2}$, upper quartile $=0.202 \mathrm{kPa} . \mathrm{s} / \mathrm{dl}^{2}$, lower quartile $=$ $\left.0.106 \mathrm{kPa} . \mathrm{s} / \mathrm{dl}^{2}\right)$. This decrease was also exhibited in the group wearing the nasal splint $\left(\right.$ median fall $\left.=0.136(0.215-0.105) \mathrm{kPa} . \mathrm{s} / \mathrm{dl}^{2}\right)$. These changes were significant in both groups $(\mathrm{p}<0.001$ and $\mathrm{p}=0.043$ respectively). There was a significant fall in total nasal resistance on applying the splint at rest (median fall $=0.199$ $\left.(0.279-0.144) \mathrm{kPa} . \mathrm{s} / \mathrm{dl}^{2}, \mathrm{p}<0.001\right)$ but there was no significant difference between the groups with or without the splint after exercise (median fall $=0.006(0.04-0.004) \mathrm{kPa} . \mathrm{s} / \mathrm{dl}^{2}, \mathrm{p}$ $=0.167)$.

\section{Discussion}

Isotonic exercise has a profound effect on the nasal mucosa and hence airway resistance. The narrowest part of the nasal airway is known to be the nasal valve anteriorly, therefore the wearing of an external nasal splint to widen this area should help athletes to gain better airflow and increase minute volumes thereby increasing lung efficiency. This study shows that this is the case for subjects at rest. Once isotonic exercise has been commenced, however, the improvement is not sustained, as the exercise itself is a more potent decongestant. The study therefore shows that the wearing of an external nasal splint in the normal subject is of no use in isotonic exercise.

1 Bridger GP. Physiology of the nasal valve. Arch Otolaryngol 1970;92:543-53.

2 Van Dishoeck HAE. The part of the valve that turbinates in total nasal resistance. International Rhinology 1965;3:1926 .

3 Richerson HB, Seebohm PM. Nasal airway response to exercise. F Allergy 1968;41:269.

4 Jones AS, Lancer JM, Stevens JC, et al. Nasal resistance to airflow: its measurement, reproducibility and normal parameters. F Laryngol Otol 1987;101:800-8.

5 Ganong WF. Cardiovascular homeostasis in health and disease. In: Review of medical physiology. London: Appleton and Lange, 1989:536. 